IN brief

\section{Millionaire's gift to San Diego}

Businessman and philanthropist T. Denny Sanford committed \$100 million this November to create a stem cell center at the University of California in San Diego (UCSD). The Sanford Stem Cell Clinical Center will be directed by Lawrence Goldstein, who already directs UCSD's stem cell research and the existing Sanford Consortium for Regenerative Medicine. "The goal is very straightforward," Goldstein says, "and that is to accelerate the development of stem cell-based therapies for patients with intractable diseases." As San Diego already has many stem cell research institutions, Goldstein says the new center will seek to provide a "shared pipeline" to help those institutions identify therapeutic candidates for human trials. The center will also include a counseling component to advise patients on emerging therapies. One important investment will be in staff to guide researchers through the "regulatory gauntlet." Stem cell biologist Chad Cowan, a program director principal faculty at the Harvard Stem Cell Institute in Cambridge, Massachusetts, welcomes the regulatory support: "I think it's a smart move on Larry's part to consider investing some of the funds in the people who will actually educate the FDA [US Food and Drug Administration] to help pave the way for their translational trials." The gift, he says, "has the opportunity to put San Diego on the map, sort of the way the Broad Institute has for [Boston]."

\section{FDA tows personalized line}

The US Food and Drug Administration (FDA) on October 29 released a report describing the agency's ongoing efforts to improve its regulatory policies for personalized medicine. The report, titled Paving the Way for Personalized Medicine: FDA's Role in a New Era of Medical Product Development, falls short of outlining any new regulatory pathways but does offer a resource to help companies with such products in development to navigate the FDA. From 2009, when the agency created a personalized medicine staff within the device center's Office of In Vitro Diagnostics and Radiological Health, it has been intensifying its commitment to the field. In 2011, the agency's biologics center created a personalized medicine team. The recent report lists 22 guidance documents related to personalized medicine and numerous organizational changes at the agency to streamline regulatory oversight. But challenges remain. Coordinating regulatory oversight of therapeutics and their companion diagnostics requires expertise from multiple FDA centers. The process is complicated, and the agency stressed in the report that companies should communicate with the FDA early and frequently. "The biggest take-home message from this report is: When you are putting your program together for your company, you need to get in touch with the FDA and start a dialog," says Philip Arlen, CEO at Precision Biologics in Rockville, Maryland. "They are saying, 'Engage us'." only tyrosine kinase inhibitor active against the T315I mutation, for instance (about $20 \%$ of all BCR-ABL mutations are T315I). Iclusig's label was broader than for just those patients with the T315I mutation, though: it was indicated for all adults with chronic, accelerated or blast-phase CML, resistant or intolerant to prior TKI therapy, and for those with Philadelphia chromosomepositive, acute lymphoblastic leukemia that is resistant or intolerant to prior TKI therapy. "Pulling ponatinib is most problematic for T315I patients. Virtually all others have other [treatment] options," declares Peter Emanuel, director of the Winthrop P. Rockefeller Cancer Institute at the University of Arkansas for Medical Sciences in Little Rock. Ultimately, bone marrow transplant remains an option for some patients, too.

The fact that there are other treatments for CML likely influenced FDA's decision to pull Iclusig completely (the European Medicines Agency on November 22 only restricted the drug's use, though a further review announced December 6 may lead to additional changes). Indeed, Sprycel (dasatinib) and Tasigna (nilotinib) treat "most" of the mutations that develop as a result of Gleevec usage, according to Emanuel. But FDA may also have wanted to act firmly to avoid potential criticism of the accelerated pathway if further issues arose later on.

There are precedents for drug withdrawals, but not many. Even fewer return to market. The best-known come-back story is Cambridge, Massachusetts-based Biogen Idec's Tysabri (natalizumab) for multiple sclerosis. Tysabri was withdrawn in 2005 after reports connecting it to a rare viral disease that affects the brain and returned just over a year later with a boxed warning and risk management program. London-based AstraZeneca's lung cancer drug Iressa (gefitinib), restricted and ultimately withdrawn in the US, found a target subgroup among Asian patients with EGFR mutations.

So, was the agency too hasty in allowing Iclusig onto the market, and/or too generous with its label, given the limited data available at approval?

Yes, according to critics of the accelerated approval program, such as political scientist and Harvard University professor of government Daniel Carpenter. The current approval system is a "growing hodgepodge of exceptions to the rule of rigorous premarket review," Carpenter told Reuters in October 2013. He pointed to a study published just before Iclusig's withdrawal showing that drugs approved in 2008 under FDA's accelerated program had been tested, on average, in less than one-fifth the number of patients that drugs approved normally are, with many safety questions remaining unanswered as a result (http://archinte.jamanetwork.com/ article.aspx?articleID=1761917).

But some see Iclusig's withdrawal as proof that the system is working as it should. "What has occurred...is a clear demonstration that the accelerated approval pathway works," noted Mikkael Sekeres, chair of FDA's Oncology Drugs Advisory Committee, on November 26 in Oncology Times. Emanuelwho follows hundreds of CML patients-also thinks FDA was right to withdraw Iclusig, given the data. Yet despite the withdrawal, "I don't think FDA needs to be more cautious when it comes to cancer," he declares. "It's a balancing act. I don't think anyone could have foreseen that this TKI would have [such severe] cardiovascular side effects; nor should we jump to the conclusion and say all TKIs will have cardiovascular effects."

The other problem is that cardiovascular side effects come in various shapes and sizes, and the methods used in cancer drug trials to screen for, and categorize, these events remain unstandardized. Indeed, Ariad claims that FDA, since approving the drug, changed its definition of a "serious adverse event." At approval, it used "the standard US regulatory definition," according to the company's chief medical officer and senior vice president clinical R\&D Frank Haluska, talking on Ariad's third quarter results call on November 12. Yet the more recent FDA statistics used to back up the decision to withdraw were based on "a new definition of events... with more kinds of events clumped together, and more adverse events categorized as serious adverse events,' Haluska said. Had the same definitions been applied as at the time of approval, FDA's headline rates for serious adverse events would have been halved, from $48 \%$ to $22 \%$ in the phase 1 trial and from $24 \%$ to $12 \%$ in the phase 2 trial.

Despite the set-back, Ariad is still betting on Iclusig's potential to match the unmet clinical need. Fewer than half of CML patients resistant or intolerant to two or more TKIs have the mutation, according to 2011 data from UK-based research group Ipsos Healthcare. Ariad CEO Harvey Berger also points to FDA reports of over 200 US patients in the last month accessing Iclusig through single-patient Investigational New Drug applications, the only way to obtain Iclusig when it was withdrawn.

Dosing may also be tweaked to improve the risk-benefit profile. Data presented by Ariad at the American Society of Hematology (ASH) meeting in early 